\title{
The clinical analysis of small supernumerary marker chromosomes in 17 children with mos 45,X/46,X,+mar karyotype
}

\author{
HONGYING WANG $^{1 *}$, TING WANG $^{2 *}$, NAICHAO YANG ${ }^{1}$, YAXIANG HE $^{1}$, \\ LINQI CHEN ${ }^{1}$, LIYI HONG ${ }^{1}$, XUEJUN SHAO ${ }^{1}$, HONG LI $^{2}$, HONG ZHU $^{1}$ and HAIBO ${ }^{2}$ \\ ${ }^{1}$ Department of Clinical Laboratory, Children's Hospital of Soochow University, Suzhou, Jiangsu 215003; ${ }^{2}$ Center for \\ Reproduction and Genetics, Suzhou Hospital Affiliated to Nanjing Medical University, Suzhou, Jiangsu 215002, P.R. China
}

Received January 29, 2016; Accepted January 13, 2017

DOI: $10.3892 / 01.2017 .5965$

\begin{abstract}
Small supernumerary maker chromosome (sSMC) is a type of structurally abnormal chromosome. In order to identify the origin, morphology and other characteristics of sSMCs in children with mos 45,X/46,X,+mar karyotype, 17 patients (16 females and 1 male) were analyzed. All patients underwent general physical examination, gonadal imaging and molecular cytogenetic analyses, including Giemsa banding, dual-color fluorescence in situ hybridization and detection of the sex-determining region $\mathrm{Y}$ gene by polymerase chain reaction. Cytogenetic analyses indicated sSMCs in 14/17 cases were derived from the $\mathrm{X}$ chromosome, of which 8 individuals presented with ring-shaped sSMCs and 6 with centric minute-shaped sSMCs. The remaining 3 cases were derived from the $\mathrm{Y}$ chromosome, and all presented with minute-shaped sSMCs. All female patients exhibited short stature, gonadal dysgenesis and other typical features of Turner syndrome. The male patient exhibited short stature, hypospadias and bilateral cryptorchidism. In conclusion, the majority of the sSMCs in patients with a mos 45,X/46,X,+mar karyotype were derived from the sex chromosomes. The molecular cytogenetic features of sSMCs may provide useful information for genetic counseling, prenatal diagnosis and individualized treatment.
\end{abstract}

Correspondence to: Dr Haibo Li, Center for Reproduction and Genetics, Suzhou Hospital Affiliated to Nanjing Medical University, 26 Daoqian Street, Suzhou, Jiangsu 215002, P.R. China

E-mail: lihaibo-775@163.com

Dr Hong Zhu, Department of Clinical Laboratory, Children's Hospital of Soochow University, 92 Zhongnan Street, Wuzhong, Suzhou, Jiangsu 215003, P.R. China

E-mail: zhhg883@sina.com

${ }^{*}$ Contributed equally

Key words: small supernumerary maker chromosome, fluorescence in situ hybridization, turner syndrome

\section{Introduction}

Small supernumerary maker chromosome (sSMC) is defined as a structurally abnormal chromosome that cannot be characterized clearly by conventional cytogenetic banding. sSMCs can be present in normal and abnormal karyotypes such as the Turner syndrome karyotype (sSMC ${ }^{\mathrm{T}}$ ) (1). The majority of patients with Tuner syndrome exhibit a short stature. The birth heights of infants with Turner syndrome are shorter than infants without the syndrome, and the growth rate of infants with Turner syndrome is also lower (2). Another feature of Turner syndrome is the abnormal development of gonads, and mental disabilities may also be present (3).

In the majority of cases, the size of sSMC is smaller than chromosome $20(4,5)$ and sSMCs can be derived from autosomes and sex chromosomes (6). sSMCs may result from translocations, with $\sim 64 \%$ attributed to balanced translocations in the parent, while the remaining $\sim 36 \%$ arise de novo (7).

The sex-determining region on the Y chromosome (SRY) gene isolated in 1990 was known as the testis-determining factor on the Y chromosome $(8,9)$. The SRY gene encodes a transcription factor, which is a member of the high mobility group box family of proteins and is important for the sex determination process (10). Although birds and reptiles lack the SRY gene, sex determination by the SRY gene is common in mammals and it can be used as a potential marker for sex determination in research (11).

Previous clinical studies reported great heterogeneity in the origins of sSMCs (12). Therefore, it is important to investigate a larger number of sSMC cases in order to expand the current understanding of the origins of sSMCs and the correlation between karyotype and phenotype, which may improve genetic counseling. In the present study, the sSMCs in 17 patients with a mos 45,X/46,X,+mar karyotype were characterized.

\section{Materials and methods}

Participants and physical examination. Ethical approval was granted by Children's Hospital of Soochow University (Suzhou, China). The informed consents were obtained from all the participants. A total of 17 patients (1 male and 16 females) were included in the present study. All patients presented with a mos 45,X/46,X,+mar karyotype, a short stature and abnormal 
Table I. Clinical feature of the small supernumerary marker chromosome in children with mos 45, X/46,X,+mar karyotype.

\begin{tabular}{|c|c|c|c|c|c|c|c|}
\hline $\begin{array}{l}\text { Case } \\
\text { No. }\end{array}$ & Gender & $\begin{array}{c}\text { Age of } \\
\text { onset (years) }\end{array}$ & $\begin{array}{l}\text { Chromosomal } \\
\text { origin of sSMC }\end{array}$ & $\begin{array}{l}\text { Shape of } \\
\text { sSMC }\end{array}$ & $\begin{array}{l}\text { SRY } \\
\text { gene }\end{array}$ & $\begin{array}{l}\text { Clinical } \\
\text { features }\end{array}$ & $\begin{array}{c}\text { Mental } \\
\text { disability }\end{array}$ \\
\hline 1 & $\mathrm{~F}$ & 9 & $X$ & $\min$ & ND & Turner & - \\
\hline 2 & $\mathrm{~F}$ & 7 & $X$ & $\min$ & ND & Turner & - \\
\hline 3 & $\mathrm{~F}$ & 16 & $X$ & $\mathrm{r}$ & ND & Turner & + \\
\hline 4 & $\mathrm{~F}$ & 6 & $X$ & $\min$ & ND & Turner & - \\
\hline 5 & $\mathrm{~F}$ & 16 & $\mathrm{X}$ & $\mathrm{r}$ & ND & Turner & - \\
\hline 6 & $\mathrm{~F}$ & 9 & $X$ & $\mathrm{r}$ & ND & Turner & - \\
\hline 7 & $\mathrm{~F}$ & 7 & $X$ & $\min$ & ND & Turner & + \\
\hline 8 & $\mathrm{~F}$ & 3 & $X$ & $\min$ & ND & Turner & - \\
\hline 9 & $\mathrm{~F}$ & 2 & $\mathrm{X}$ & $\mathrm{r}$ & ND & Turner & - \\
\hline 10 & $\mathrm{~F}$ & 5 & $\mathrm{Y}$ & $\min$ & - & Turner & - \\
\hline 11 & $\mathrm{~F}$ & 13 & $\mathrm{X}$ & $\mathrm{r}$ & ND & Turner & - \\
\hline 12 & $\mathrm{~F}$ & 6 & $\mathrm{X}$ & $\mathrm{r}$ & ND & Turner & - \\
\hline 13 & $\mathrm{~F}$ & 16 & $X$ & $\mathrm{r}$ & ND & Turner & - \\
\hline 14 & M & 6 & $\mathrm{Y}$ & $\min$ & + & $\begin{array}{l}\text { Hypospadias, } \\
\text { short stature }\end{array}$ & - \\
\hline 15 & $\mathrm{~F}$ & 2 months & $\mathrm{Y}$ & $\min$ & + & Turner & - \\
\hline 16 & $\mathrm{~F}$ & 9 & $X$ & $\mathrm{r}$ & ND & Turner & + \\
\hline 17 & $\mathrm{~F}$ & 1 & $X$ & $\min$ & ND & Turner & - \\
\hline
\end{tabular}

SRY, sex determining region Y; sSMC, small supernumerary maker chromosome; r, ring chromosome; min, centric minute; ND, not detected; Turner, Turner syndrome; F, female, M, male; +, positive; -, negative.
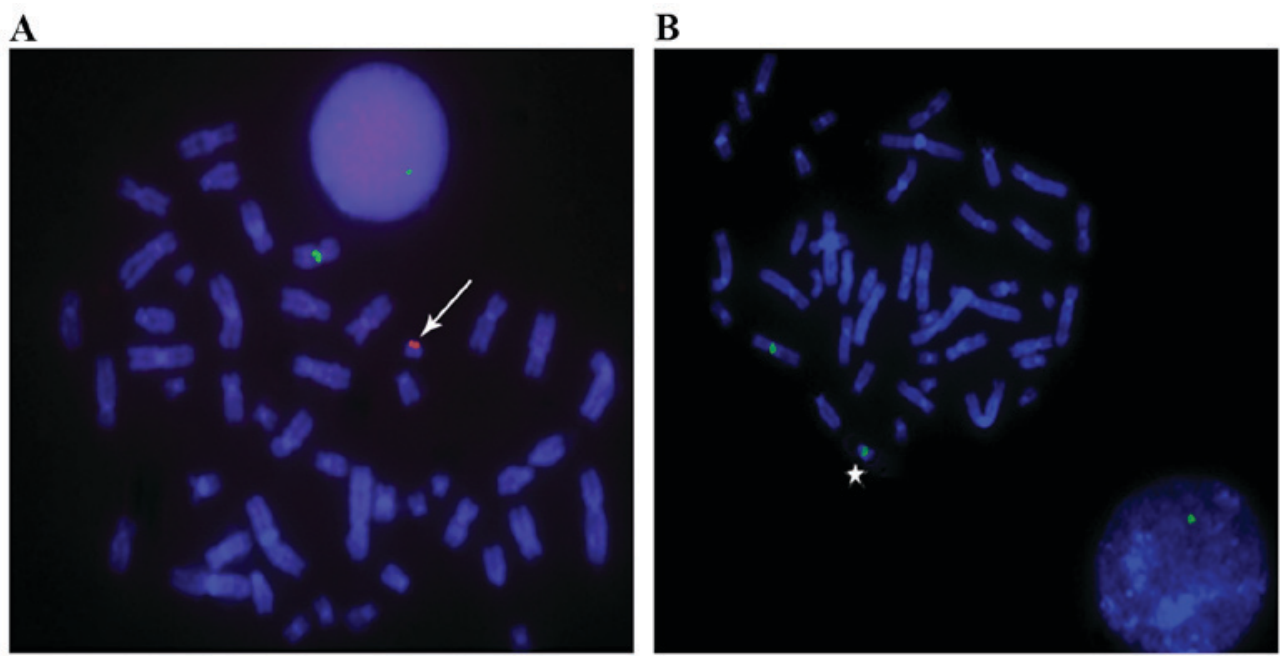

Figure 1. Dual-color FISH of sSMC in patients with 45,X/46,X,+mar mosaicism. The X chromosome centromere was stained green, while the Y chromosome was stained red, using FISH methods. (A) A chromosome spread from a patient, including an sSMC derived from the Y chromosome (red, arrowhead). During metaphase, the DAPI chromosome signal was 46,X,+mar; in interphase, it was 45,XO. (B) A chromosome spread from a patient with mosaicism, including an sSMC derived from the X chromosome (green, star). During metaphase, the DAPI chromosome signal was 46, X, +mar; in interphase, it was 45,XO. Magnification, x1,000. FISH, fluorescence in situ hybridization; sSMC, small supernumerary maker chromosome.

development of the gonads. The average age of the patients was 7.4 years, ranging from 2 months to 16 years. The stature of the children was shorter than the children of the same age.

Physical examinations were performed in all 17 patients and the gonads were assessed by imaging. The Wechsler Intelligence Scale for Children-V was employed to evaluate the intellectual ability of the participants (13).
Cytogenetic analysis. Metaphase chromosomes were obtained from phytohaemagglutinin stimulated lymphocyte cultures from biopsy samples as previously described (14). The chromosomes were analyzed by Giemsa banding and karyotyped according to the Use of the International System for Human Cytogenetic Nomenclature (15). Karyotypes were based on the analysis of 50 metaphases. 

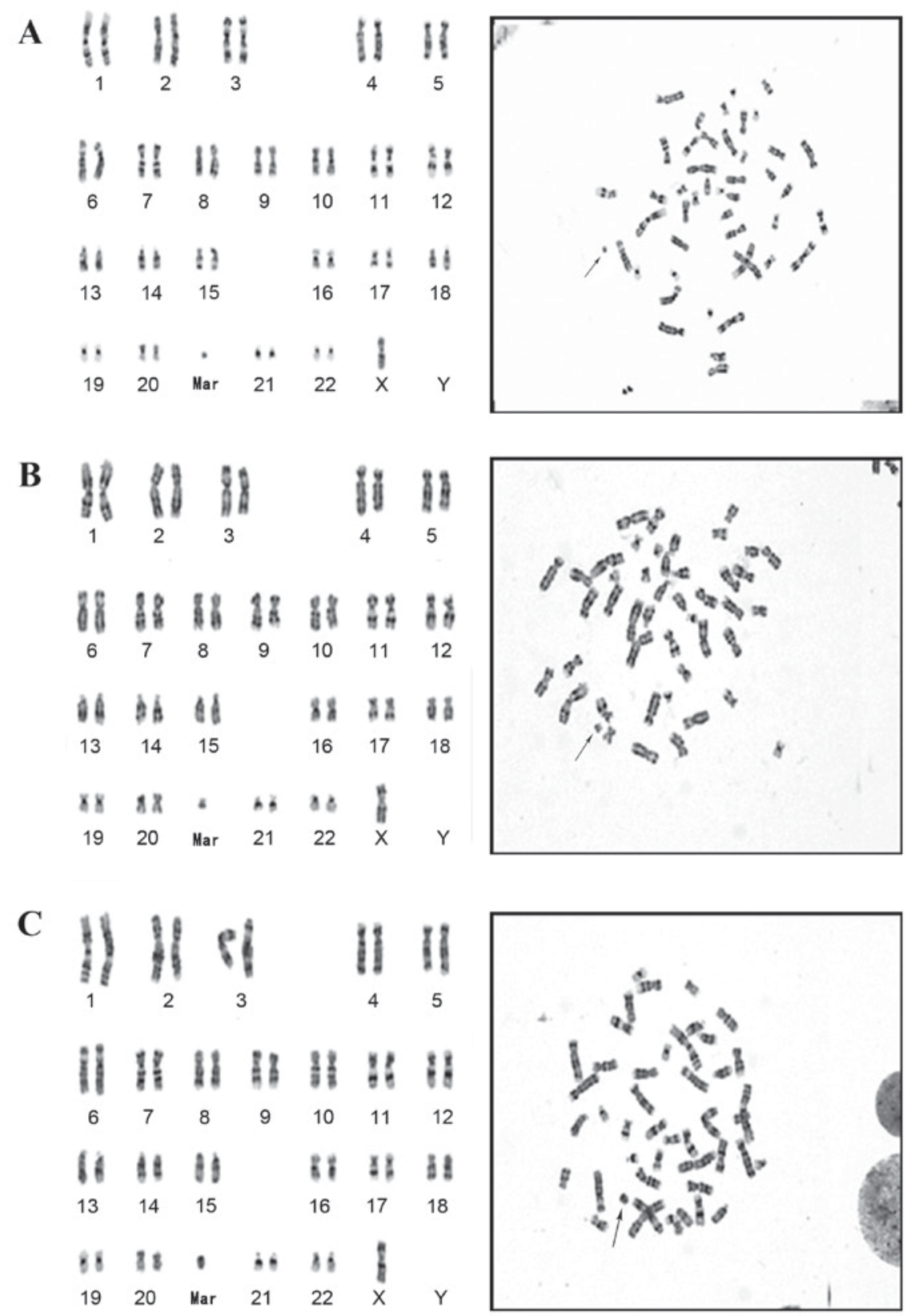

Figure 2. Karyotaping detected by Giemsa banding. sSMCs are indicated by black arrows. (A) Centric minute-shaped sSMC derived from the Y chromosome. (B) Centric minute-shaped sSMC derived from the X chromosome. (C) Ring-shaped sSMC derived from the X chromosome. sSMC, small supernumerary maker chromosome.

Fluorescence in situ hybridization (FISH). FISH was performed using commercially available centromeric probes for chromosomes X and Y (Cytocell Ltd., Cambridge, UK) according to the manufacturer's protocol (16). The metaphase chromosomes of the samples from the patients were analyzed. The DNA was counterstained with DAPI. The chromosome $X$ $\alpha$-satellite (DXZ1) probe hybridized to sequences located at Xp11.1-q11.1 and the chromosome Y satellite III probe (DYZ3) hybridized to sequences located at Yp11.1-q11.1. The image was analyzed using a FISH image acquisition system (LEICA Q55OCW).

Polymerase chain reaction (PCR). Samples from patients with sSMCs derived from the $\mathrm{Y}$ chromosome were analyzed by PCR to detect the presence of the SRY gene. Genomic DNA was extracted from the blood samples using the QIAamp DNA Blood Mini Kit (Qiagen GmbH, Hilden, Germany) according to the manufacturer's protocol. PCR reactions were performed in $10 \mu \mathrm{l}$ reactions containing $20 \mathrm{mg}$ genomic DNA, $0.4 \mu \mathrm{M} / 1$ primers, $60 \mu \mathrm{M} / 1$ deoxynucleotide triphosphates, $2 \mathrm{mM} / 1 \mathrm{MgCl}_{2}, 0.5$ units of DNA polymerase and $1 \mu \mathrm{l} 10 \mathrm{X}$ Taq PCR MasterMix (HotStarTaq Master Mix Kit, Qiagen GmbH).

PCR cycling conditions included, $95^{\circ} \mathrm{C}$ for $6 \mathrm{~min}$, followed by 35 cycles at $95^{\circ} \mathrm{C}$ for $45 \mathrm{sec}, 58^{\circ} \mathrm{C}$ for $45 \mathrm{sec}$, an extension step at $72^{\circ} \mathrm{C}$ for $60 \mathrm{sec}$ and a final extension step at $72^{\circ} \mathrm{C}$ for $7 \mathrm{~min}$. The sequence for the forward primer was $5^{\prime}$-GAA TATTCCCGCTCTCCGG-3' and for the reverse primer was 5'-ACAACCTGTTGTCCAGTTGC-3'. The agarose gel was visualized with a BIO-RAD VersaDoc 3.0 (Bio-Rad Laboratories, Inc., Hercules, CA, USA). 


\section{Results}

Incidence rates of SSMC. The incidence of SSMC in males was markedly decreased compared to the incidence in girls. Out of a total of 477 females presented with short stature and abnormal gonadal development, sSMC was detected in 16 patients with Turner syndrome (sSMC ${ }^{\mathrm{T}}$ ) at a detection rate of $\sim 3.4 \%$. Out of a total of 349 males also presenting with short stature and abnormal gonadal development, sSMC was detected in only 1 case, with a detection rate of $\sim 0.29 \%$.

Origin and morphology of sSMC. Dual-color FISH analysis with DXZ1 (green) and DYZ3 (red) probes was employed to assess the origin of sSMCs (Fig. 1). Out of the 16 females detected with SMCs, sSMCs in 14 cases were derived from the $\mathrm{X}$ chromosome and 2 cases were derived from the $\mathrm{Y}$ chromosome. The sSMC in the single male was derived from the $\mathrm{Y}$ chromosome (Fig. 2).

Karyotype and FISH analyses indicated out of the 17 cases with sSMCs, 8 cases were ring-shaped and 9 were centric minute-shaped sSMC. The results demonstrated that the $\mathrm{sSMC}^{\mathrm{T}}$ cases were derived from the sex chromosome, including predominantly from the $\mathrm{X}$ chromosome.

Detection of the SRY gene. The sSMCs in 2 females (cases 10 and 15) and 1 male (case 14) were derived from the Y chromosome. PCR analysis indicated that the SRY gene was detected in only cases 14 and 15 (Table I). Both individuals exhibited feminine characteristics. Although the SRY gene was present in case 15, the gene may have been mutated, leading to a loss-of-function. The Wechsler Intelligence Scale for Children-V test indicated that 3 (cases 3, 7 and 16) of the 17 children tested appeared to have mental retardation (Table I).

\section{Discussion}

The incidence rate of sSMC is relatively low, with a rate of $\sim 0.001 \%$ in newborn babies and a detection rate of $\sim 0.004 \%$ by antenatal diagnosis (1). In the present study, the incidence of sSMC in males was markedly lower compared to the incidence in girls, with $\sim 0.29$ vs. $\sim 3.4 \%$.

sSMCs can be derived from the autosomes and the sex chromosomes (6). Liehr et al (1) have previously tested the origins of sSMCs in 512 cases, and it was reported that $72.6 \%$ were derived from the $\mathrm{Y}$ chromosome, $27 \%$ from the $\mathrm{X}$ chromosome and $0.4 \%$ from the autosomes. In the present study, 17 cases were analyzed using dual-color FISH. It has been demonstrated that the sSMCs in patients with a Turner syndrome karyotype were derived from the sex chromosomes. In the 16 females, sSMCs in 14 cases were derived from the $\mathrm{X}$ chromosome and sSMCs in 2 cases were derived from the $\mathrm{Y}$ chromosome. The sSMC in the single male with hypospadias and a short stature was derived from the Y chromosome.

It has been previously reported that the origin of the sSMC in patients with Turner syndrome may impact on the risk of malignant gonadal tumor; if the sSMC is derived from the $\mathrm{Y}$ chromosome the risk may be increased by $30 \%$ (17). Therefore, it is important to establish the origin of sSMCs.
$45, \mathrm{X} / 46, \mathrm{XY}$ is a disorder of sexual development (DSD). Patients with DSDs present with abnormal sexual development and short stature (18). Types of DSD include Turner syndrome, mixed gonadal dysgenesis and genital tract malformation $(17,19,20)$. In the present study, sSMCs in 3 patients ( 3 females and 1 male) were derived from the $\mathrm{Y}$ chromosome. The SRY gene in case 15 may have been mutated, leading to a loss-of-function. Notably, cases 10 and 15 were females, and whilst the SRY gene was absent in case 10, the gene was present in case 15 . Both females exhibited feminine characteristics and clinical characteristics associated with Turner syndrome.

In view of the short stature and abnormal sexual development, patients with these features may be treated as Turner syndrome patients. When treating 45,X/46,X,+mar karyotype patients, the origin of sSMCs need to be assessed. To keep the basic social gender and gonad function, the contradictory gonad should be excised. During childhood, Turner syndrome patients may be treated with recombinant human growth hormone to promote an increase in stature. Patients would be treated with hormone to initiate puberty $\sim 12$ years old (21). In addition, mental intervention is also necessary to treat the children.

In conclusion, patients with the mos $45, \mathrm{X} / 46, \mathrm{X},+$ mar karyotype have varying origins of sSMC. A multidisciplinary approach is necessary for early diagnosis and appropriate treatment of these patients in order to reduce social and mental consequences.

\section{Acknowledgements}

The authors thank the patients for participating in the present study. The present study was supported by the grant of Jiangsu province Association of Maternal and Child Health (grant no. FYX201603), Jiangsu Provincial Medical Youth Talent (grant no. QNRC2016238), Suzhou Science and Technology support program (grant no. SS201647), and Suzhou Key Medical Center (grant no. Szzx201505)

\section{References}

1. Liehr T, Mrasek K, Hinreiner S, Reich D, Ewers E, Bartels I, Seidel J, Emmanuil N, Petesen M, Polityko A, et al: Small supernumerary marker chromosomes (sSMC) in patients with a 45,X/46,X,+mar karyotype-17 new cases and a review of the literature. Sex Dev 1: 353-362, 2007.

2. Davenport ML, Punyasavatsut N, Stewart PW, Gunther DF, Sävendahl L and Sybert VP: Growth failure in early life: An important manifestation of turner syndrome. Horm Res 57: 157-164, 2002.

3. Fjermestad KW, Naess EE, Bahr D and Gravholt CH: A 6-year follow-up survey of health status in middle-aged women with turner syndrome. Clin Endocrinol (Oxf) 85: 423-429, 2016.

4. Liehr T, Claussen U and Starke H: Small supernumerary marker chromosomes (sSMC) in humans. Cytogenet Genome Res 107: 55-67, 2004.

5. Ou J, Wang W, Liehr T, Klein E, Hamid AB, Wang F, Duan C and $\mathrm{Li} \mathrm{H}$ : Characterization of three small supernumerary marker chromosomes (sSMC) in humans. J Matern Fetal Neonatal Med 26: 106-108, 2013.

6. Soheilipour F, Abed O, Behnam B, Abdolhosseini M, Alibeigi P and Pazouki A: A rare case of mixed gonadal dysgenesis with mosaicism 45, X/46, X, +mar. Int J Surg Case Rep 7C: 35-38, 2015.

7. Trifonov V, Fluri S, Binkert F, Nandini A, Anderson J, Rodriguez L, Gross M, Kosyakova N, Mkrtchyan H, Ewers E, et al: Complex rearranged small supernumerary marker chromosomes (sSMC), three new cases; evidence for an underestimated entity? Mol Cytogenet 1: 6, 2008. 
8. Jäger RJ, Anvret M, Hall K and Scherer G: A human XY female with a frame shift mutation in the candidate testis-determining gene SRY. Nature 348: 452-454, 1990 .

9. Iida T, Nakahori Y, Komaki R, Mori E, Hayashi N, Tsutsumi O, Taketani Y and Nakagome Y: A novel nonsense mutation in the HMG box of the SRY gene in a patient with XY sex reversal. Hum Mol Genet 3: 1437-1438, 1994.

10. Moreira MA: SRY evolution in Cebidae (Platyrrhini: Primates). J Mol Evol 55: 92-103, 2002.

11. Wu QY, Li N, Li WW, Li TF, Zhang C, Cui YX, Xia XY and Zhai JS: Clinical, molecular and cytogenetic analysis of 46, XX testicular disorder of sex development with SRY-positive. Bmc Urol 14: 70, 2014

12. Melo JB, Matoso E, Polityko A, Saraiva J, Backx L, Vermeesch JR, Kosyakova N, Ewers E, Liehr T and Carreira IM: Molecular cytogenetic characterization of two cases with de novo small mosaic supernumerary marker chromosomes derived from chromosome 16: Towards a genotype/phenotype correlation. Cytogenet Genome Res 125: 109-114, 2009.

13. Na SD and Burns TG: Wechsler intelligence scale for children-V: Test review. Appl Neuropsychol Child 5: 156-160, 2016.

14. Sheth F, Ewers E, Kosyakova N, Weise A, Sheth J, Desai M, Andrieux J, Vermeesch J, Hamid AB, Ziegler M and Liehr T: A small supernumerary marker chromosome present in a Turner syndrome patient not derived from X- or Y-chromosome: A case report. Mol Cytogenet 2: 22, 2009.
15. Gonzalez Garcia JR and Meza-Espinoza JP: Use of the International system for human cytogenetic nomenclature (ISCN). Blood 108: 3952-3953, 2006.

16. Liehr T, Mrasek K, Weise A, Dufke A, Rodríguez L, Martínez Guardia N, Sanchís A, Vermeesch JR, Ramel C, Polityko A, et al: Small supernumerary marker chromosomes-progress towards a genotype-phenotype correlation. Cytogenet Genome Res 112: 23-34, 2006.

17. Alvarez-Nava $\mathrm{F}$ and Puerta $\mathrm{H}$ : Y-chromosome microdeletions in 45,X/46,XY patients. Am J Med Genet A 140: 1128-1130, 2006.

18. Layman LC, Tho SP, Clark AD, Kulharya A and McDonough PG: Phenotypic spectrum of $45, \mathrm{X} / 46, \mathrm{XY}$ males with a ring $\mathrm{Y}$ chromosome and bilaterally descended testes. Fertil Steril 91: 791-797, 2009.

19. Chang GY, Dong ZY, Wang W, Xiao Y, Chen FS, Ni JH, Wang RF and Wang DF: Association of 45, X/46, XY mosaicism with disorders of sex development: The clinical analysis of 5 cases. Zhonghua Er Ke Za Zhi 49: 451-454, 2011 (In Chinese).

20. Hughes IA, Houk C, Ahmed SF and Lee PA; Lawson Wilkins Pediatric Endocrine Society/European Society for Paediatric Endocrinology Consensus Group: Consensus statement on management of intersex disorders. J Pediatr Urol 2: 148-162, 2006.

21. Gravholt $\mathrm{CH}$ : Hormone replacement therapy in turner syndrome is important-a new meta-analysis points at many shortcomings in the available literature. Endocrine 55: 329-330, 2017. 